\title{
RELAÇÕES ENTRE O DESIGN PARTICIPATIVO E PRINCÍPIOS PEDAGÓGICOS FREIREANOS
}

\author{
CANÔNICA, Rosangela; Mestranda em Design; UNIVILLE. \\ canonica.rosangela@gmail.com.br \\ PEIXE, Rita Inês Petrykowski; Doutora em Educação; UFRGS. \\ ritapeixe@hotmail.com \\ SANTOS, Adriane Shibata; Doutora em Design; PUC-RIO. \\ adriane.shibata@univille.net \\ KOHLS, Christian; Bacharel em Engenharia Florestal; UFPR. \\ ckohls@zipmail.com.br
}

Resumo: O presente trabalho propõe uma reflexão integrada de pesquisas relacionadas às práticas participativas no design e a educação participativa Freireana, considerando os métodos colaborativos do design e enfatizando as relações existentes entre seus princípios metodológicos e as do educador Paulo Freire, acerca de uma educação libertadora, dialógica e socialmente produtiva. A base de sua fundamentação analisa as relações entre abordagens metodológicas do design, sendo a Técnica do Brainstorming e as fases do Design Thinking, associadas a pressupostos Freireanos, estabelecidas à luz de práticas pedagógicas coletivas e partilhadas, que tecem um universo comum entre todos os sujeitos envolvidos na busca de soluções para problemas.

Palavras-chave: Design participativo, princípios metodológicos, pedagogia Freireana.

\begin{abstract}
This paper proposes an integrated reflection of research related to participatory design practices in the Freirean and participatory education, considering collaborative design methods and emphasizing the relations between its methodological principles and the educator Paulo Freire, about a liberating education, dialogic and socially productive. The basis of his reasoning analyzes the relationship between methodological approaches to the design, with the Technical Brainstorming and phases of design thinking, associated with Freire's assumptions established in the light of collective and shared pedagogical practices that weave a common universe among all subjects involved in finding solutions to problems.
\end{abstract}

Keywords: participatory design, methodological principles, Freirean pedagogy. 


\section{INTRODUÇÃO}

Procura-se, neste artigo, estabelecer uma abordagem de convergência entre o campo teórico dos processos participativos em design e as teorias do educador Paulo Freire, refletindo acerca das práticas evidenciadas no processo metodológico ativo, dialogal e participativo.

Ponderar um modo participativo de criar soluções parte de um pensamento em design que não se limite apenas a designers, mas que se estenda a outros contextos. Isso possibilita que os agentes envolvidos vivenciem uma educação socialmente produtiva, combinando desafio e criatividade, o que reflete em mudanças e atitudes, bem como um maior envolvimento e dedicação entre todos para solução de problemas.

Mesmo que não explicitada, é perceptível a presença dos pressupostos de Paulo Freire nos processos de design, tanto no que se refere a adoção de metodologias, quanto na abordagem de espaços compartilhados, enfatizando a importância da autonomia do indivíduo em seus processos, ratificada através do diálogo e conscientização, os quais propõem ações de colaboração.

Em determinados campos do design, essa relação pode ser mais perceptível, considerando a área social, mais especificamente o terceiro setor, onde os desafios relacionam-se, além de projetos materiais com resultados tangíveis, projetos outros, os quais incorporam ações de ensino-aprendizagem determinantes para o empoderamento de pessoas em processo de transformação social.

O design social tem como proposito, na abordagem pedagógica, estabelecer bases de criação junto a pessoas em situação de desigualdade social, buscando soluções para seus problemas, com a responsabilidade de fomentar autogestão e o empoderamento, de modo que a comunidade possa, a partir de suas experiências, gerar trabalho e renda para melhoria da sua qualidade de vida. O designer, enquanto sujeito, conduz atividades em grupo, assumindo o papel de facilitador, mediando a aprendizagem e promovendo a troca de saberes. É, portanto, educador. Apropriandose de princípios metodológicos colaborativos, favorece a participação e o envolvimento de todos. Ao adotar esse posicionamento, se estabelece a conexão com o pensamento Freireano que orienta a prática libertadora do individuo, colocando-o, não mais como objeto da desigualdade social, mas como protagonista de sua própria história de vida.

Essa relação Freireana - embora muitas vezes não explicitada - pode ser percebida nos vários âmbitos de atuação do designer: em contextos educacionais onde atua como educador presente na sala de aula (ou no chão batido da comunidade) como também em atividades colaborativas nas mais diferentes etapas dos processos metodológicos de P\&D (pesquisa e design), nas quais a opção por procedimentos de caráter participativo é fundamental para a condução de seus projetos. Esses espaços, também pensados para a prática participativa, direcionam ao pensamento de Freire, constituindo um layout onde as pessoas são envolvidas em uma atmosfera criativa e libertadora.

Nesse sentido, justifica-se discutir o design participativo em relação ao pensamento Freireano, de modo a sistematizar as conexões existentes entre esses campos do saber. Tendo como fundamento a pesquisa bibliográfica em materiais que versam sobre o tema, o escopo da presente reflexão busca destacar a importância do 
design no âmbito pedagógico e vice-versa, visando construir criativamente soluções significativas de ensino-aprendizagem. Importante considerar que ambas as áreas - a educacional e a do design social - necessitam aproximações e reciprocidades, visando enriquecer mutuamente as experiências na condução de processos metodológicos ativos, dialogais e participativos.

\section{PRINCÍPIOS DO DESIGN PARTICIPATIVO}

Historicamente, o design participativo surge na Escandinávia, no final dos anos 60 e inicio dos anos 70, como uma tentativa de estabelecer gestões mais democráticas ao design sistema/produto no contexto da informatização dos postos de trabalho sob uma forte legislação trabalhista, alicerçada em valores culturais de dignidade humana, desenvolvimento pessoal, qualidade e inclusão social (MORAES \& ROSA, 2012). O objetivo consistia em melhorar a comunicação e a interação entre a indústria e o movimento sindicalista, que reivindicava que os trabalhadores tivessem um controle democrático das mudanças no ambiente, ferramentas e relações de trabalho. A partir dos anos 80, o design participativo passou a ser empregado como uma metodologia de design de produtos, processos e interfaces.

O objeto de estudo do design participativo considera como elemento importante o conhecimento tácito desenvolvido por quem participa. Cabe ressaltar que, por ser de difícil formalização e descrição, esse conhecimento adquirido ao longo da vida pela experiência, tende a ser ignorado pelos teóricos da cognição [...] (SPINUZZI, 2005 apud MORAES e ROSA, 2012).

Para Silva (2012), é notório que, à medida que avançamos no século XXI, novos problemas, mais complexos, se anunciam. E, para lidar com eles, o design precisa crescer além dos designers.

Quando um problema típico de uma área é visto pela ótica de outra, acontece um reposicionamento conceitual que levanta questões realmente novas as quais podem apontar para uma solução inovadora. Pautado nessa premissa, novas abordagens para o design oferecem métodos que estimulam a integração entre equipes interdisciplinares, distinguindo multidisciplinaridade de interdisciplinaridade:

\footnotetext{
“Em um grupo apenas multidisciplinar cada indivíduo se torna defensor de sua especialidade técnica e o projeto se torna uma negociação entre essas partes. Em um time interdisciplinar acontece a propriedade coletiva de ideias e todos se sentem responsáveis por elas" (BROWN 2009, apud SILVA, 2012).
}

O design participativo fundamenta-se no intuito de que as pessoas estão sempre interagindo nos seus processos, mesmo que não oficialmente. É importante destacar que para Forester (1999, apud AMSTEL, 2008), uma das vantagens (e desafios) dessa vertente participativa é a capacidade de incentivar pessoas a se envolverem no delineamento do futuro a partir das experiências vividas no passado e no presente. Tendo vivência real da situação, os participantes podem contribuir com propriedade, enfatizando os aspectos que Ihes são cruciais. Entretanto, como os interesses e vivências são diferenciados para cada pessoa, a todo o momento, converge-se ao debate. Por mais que algumas questões fiquem sem fechamento, a 
síntese do que é discutido é constituída de múltiplas determinações calcadas na realidade, não numa visão idealista (e monolítica) do que poderia ser e ainda não é. Além de discutir os sistemas, os participantes descobrem entre si novas visões sobre as situações vividas e o efeito destas percepções na própria situação, conscientizando-se assim do papel político do cotidiano no delineamento da própria sociedade.

Benavides-Puerto (1999) sugere que este tipo de manifestação da prática do design envolve em si a dimensão da inovação social, mais do que a dimensão da inovação tecnológica. É também alternativa política e de descolonização tecnológica. Constitui-se num tipo de design que se traduz em uma abordagem que procura trazer as pessoas servidas pelo design para o centro do processo criativo. Moraes e Santa Rosa (2012) reforçam esse posicionamento ao comentar que o design participativo possibilita que as pessoas possam vivenciar o projeto em design como se fizessem parte da equipe de trabalho.

O design participativo, ao incluir diferentes pessoas, trazendo para negociação múltiplos aspectos de uma mesma situação, sustenta sua experiência na vivência real da situação, onde os agentes envolvidos no processo podem contribuir com seus diferentes saberes para solução de problemas comuns. Como os interesses e vivências são diferenciados para cada pessoa, a negociação é um momento no qual uma rica totalidade de visões pode convergir para uma relação dialógica.

\section{PENSAMENTO FREIREANO}

De acordo com Fiori (1987), Paulo Freire é um pensador comprometido com a existência, sendo, na mesma medida, educador. Fundamenta seu pensamento em uma pedagogia na qual o esforço totalizador da práxis humana busca, na interioridade desta, retotalizar-se como "prática da liberdade". Nela, o caminho para a libertação está no oprimido que se liberta, tornando-se sujeito que se deve autoconfigurar responsavelmente.

A temática central do pensamento Freireano está no processo de mudança, consequência de uma educação libertadora. Para Gadotti (2005, p.10), ao lado da conscientização, a mudança é um "tema gerador" da prática teórica de Paulo Freire:

Como o tema da consciência, o tema da mudança acompanha todas as suas obras. A mudança de uma sociedade de oprimidos para uma sociedade de iguais e o papel da educação - da conscientização - nesse processo de mudança é a preocupação básica da pedagogia de Paulo Freire.

Ainda segundo Gadotti (2005) o educador Paulo Freire combate a concepção ingênua da pedagogia que se crê motor ou alavanca da transformação social e política. Combate, igualmente, a concepção oposta, o pessimismo sociológico, que consiste em dizer que a educação reproduz mecanicamente a sociedade. A partir dele, nasce um pensamento pedagógico que leva o educador e todo profissional a se engajar social e politicamente, bem como a perceber que as possibilidades da ação social e cultural encontram-se na luta da transformação das estruturas opressivas da sociedade classista.

Para Fiori (1987), a pedagogia Freireana pensa e pratica um método pedagógico que procura dar ao ser humano a oportunidade de (re)descobrir-se através da 
retomada reflexiva do próprio processo em que vai se descobrindo, se manifestando e se configurando - "método de conscientização". Assim, a consciência do mundo e a consciência de si crescem juntas e em razão direta; sendo uma a luz interior da outra, uma comprometida com a outra. Evidencia-se a intrínseca correlação entre conquistarse, fazer-se mais si mesmo, e conquistar o mundo, fazê-lo mais humano. Mas ninguém se conscientiza separadamente dos demais. A consciência se constitui como consciência do mundo. $\mathrm{O}$ auto (re)conhecimento plenifica-se no (re)conhecimento do outro, de modo que, no isolamento, a consciência modifica-se.

\subsection{A educação "bancária"}

Para Freire (1996), ensinar não é transferir conhecimento, mas criar possibilidades para a sua própria produção ou a sua construção. Porém, quanto mais se analisa as relações de educador-educando na escola, em qualquer de seus níveis (ou fora dela), percebe-se um caráter especial e marcante: o de serem relações fundamentalmente narradoras, dissertadoras. Ou seja, narração de conteúdos que implica em sujeito - narrador - e objeto paciente, ouvinte - educando.

A inquietação consiste em questionar uma educação que trata da realidade como algo parado, estático, compartimentado e bem-comportado, que enfatiza, muitas vezes, aspectos completamente alheios a experiência existencial dos educandos. A narração conduz à memorização mecânica do conteúdo, formando recipientes a serem "enchidos" e, quanto mais são enchidos pelo educador, à semelhança de depósitos, tanto melhor parecerá ser o processo de educar. Dessa maneira, nasce a concepção "bancária", em que a única margem de ação que se oferece é a do depósito, guardado e arquivado. Nesta distorcida visão de educação não há criatividade, não há transformação, não há saber. Assim, é indispensável considerar que só existe saber na invenção, na reinvenção, na busca inquieta, impaciente, permanente que os seres humanos fazem no mundo, com o mundo e com os outros (FREIRE, 1987). Isso supõe que:

Na visão "bancária" da educação, o "saber" é uma doação dos que se julgam sábios aos que julgam nada saber. Doação que se funda numa das manifestações instrumentais da ideologia da opressão - a absolutização da ignorância, que constitui o que chamamos de alienação da ignorância, segundo a qual esta se encontra sempre no outro (FREIRE, 1987, p.58).

Desta maneira, o educador que aliena a ignorância se mantém em posições fixas, inalteráveis. Será sempre o que sabe, enquanto os demais serão sempre os que não sabem. A rigidez dessas posições nega a educação e o conhecimento como processo de busca.

Freire (1987), interpreta a concepção "bancária", que estimula a contradição, sob diferentes vieses: (a) o educador é o que educa; os educandos, os que são educados; (b) o educador é o que sabe; os educandos, os que não sabem; (c) o educador é o que pensa; os educandos, os que pensam docilmente; (d) o educador é o que diz a palavra; os educandos, os que escutam cordatamente; (e) o educador é o que disciplina; os educandos, os disciplinados; (f) o educador é o que opta e prescreve sua opção; os educandos, os que seguem a prescrição; (g) o educador é o que atua; os 
educandos, os que têm a ilusão de que atuam, na atuação do educador; (h) o educador escolhe o conteúdo programático; os educandos, jamais ouvidos nessa escolha, se acomodam a ele; (i) o educador identifica a autoridade do saber como sua autoridade funcional, que opõe antagonicamente à liberdade dos educandos; estes devem adaptar-se às determinações daquele; (j) o educador, finalmente, é o sujeito do processo; os educandos, meros objetos. Nesse sentido, quanto mais se exercitem os educandos no arquivamento dos depósitos que lhe são feitos, tanto menos desenvolverão em si a consciência critica da qual resultaria a sua inserção no mundo, como transformadores dele. Ou seja, como sujeitos.

Uma crítica ao sistema "bancário" é observada na música "Another brick in the Wall" (um outro tijolo no muro), lançada em 1979 pela banda Pink Floyd e interpretada no filme "The Wall", produzido por Alan Parker no Reino Unido em 1982. A imagem referenciada na Figura 1 explicita o sentimento de um modelo de educação dominante e, sobretudo, alienador, que escraviza e anula o individuo na sua essência, tornando-o apenas mais um no processo produtivo. A música metaforiza o sistema educacional que, ao invés de incentivar, oprime o educando com suas exigências alienantes.

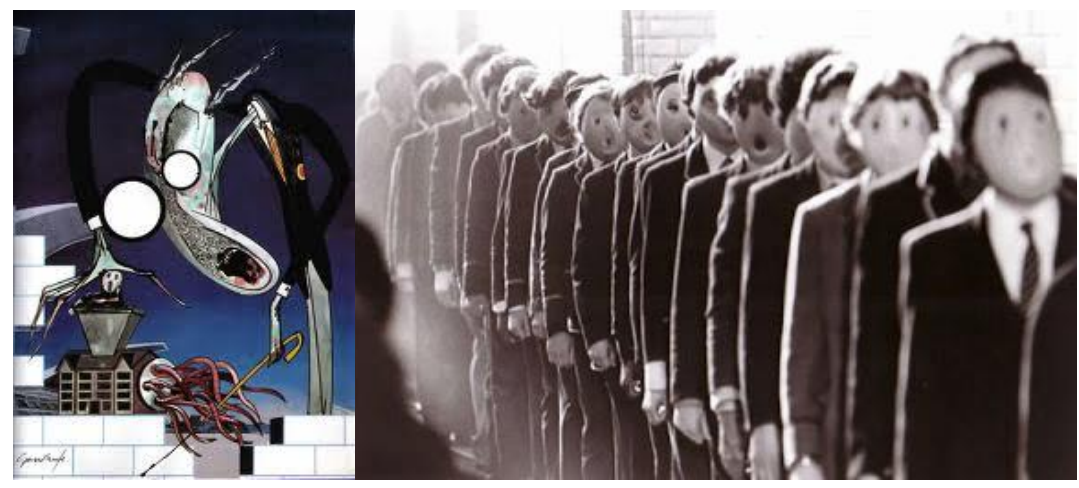

Figura 1 - "Another brick in the Wall”, Pink Floyd, 1979.

Fonte: arquivo pessoal.

Para Nascimento (2009), a crítica apresentada na música condiz com o pensamento de Freire, no qual se eleva o poder do mais forte sobre o mais fraco. Não há diversificação nas ferramentas para a conquista do saber, não existe interação, transformação ou troca de conhecimento entre ambas as partes. Tudo é desprovido de ética e a opressão é a base. Não há polarização das discussões e o centro da atenção está sempre naquele que possui o poder controlador. Não há, portanto, espaço para a livre expressão, ideais, críticas ou contra-argumentação; há apenas o dever das repetições e memorização daquilo que foi previamente indicado.

\subsection{Educação libertadora}

Segundo Freire (1987) é preciso um pensar autêntico onde a ação deve ser infundida na profunda crença no humano, no seu poder criador. Esta mudança de paradigma leva à humanização, a serviço da libertação. A educação que se impõe como prática para a libertação está fundamentada na problematização do ser humano 
e de suas relações com o mundo. Responde à essência do ser da consciência, que é a intencionalidade. A prática problematizadora leva a uma investigação crítica, ao diálogo entre o educador (facilitador dos processos) e o educando, resultando na busca pela emersão das consciências e a inserção crítica na realidade.

$\mathrm{O}$ popularmente conhecido pensamento "Ninguém educa ninguém, ninguém educa a si mesmo, os homens se educam entre si, mediatizados pelo mundo" (FREIRE, 1987, p. 70) põe em evidência a necessidade do diálogo. É por via desse caminho que se opera a relação ensino-aprendizagem, materializada na troca de saberes, onde ambos os sujeitos do processo de descoberta crescem juntos, eliminando os "argumentos de autoridade".

Nesse sentido, quanto mais provocados os educandos como seres no mundo e com o mundo, tanto mais se sentirão desafiados. Tão mais desafiados, quanto mais obrigados a responderem ao desafio. Desafiados, compreendem o desafio na própria ação de captá-lo. Mas, precisamente, porque captam o desafio como um problema e suas conexões com os outros num plano de totalidade e não como algo petrificado, a compreensão tende a tornar-se crescentemente crítica e, por consequência, cada vez mais desalienada (FREIRE, 1987).

Gutiérrez (1988), fundamentado em Freire, reforça que a opção e o compromisso de educar não se dão no plano teórico, são consequência lógica e necessária da práxis. A participação criativa e reflexiva é o meio mais eficaz de chegar à compreensão e valorização da ação pedagógica. Para o autor, ao refletir sobre sua prática - que constitui seu problema - educadores e educandos procuram encontrar uma razão existencial e seu compromisso como sujeitos da história, a qual eles, enquanto partícipes, têm obrigação de transformar mediante sua ação criadora.

A prática de pensar a prática é a melhor maneira de aprender a pensar justa e corretamente e, por sua vez, é também o modo mais adequado de melhorar a própria prática. A dialética ação-reflexão condiciona tanto o pensamento como a ação, de modo que ambos os momentos se iluminam, se valorizam e se enriquecem mutuamente. Nem a ação excessiva e mecanizada, nem a mais encantadora teoria conscientizadora, levam à verdadeira práxis. Para Freire (1974, apud GUTIÉRREZ, 1988, p.106), a consciência "não se transforma por meio de cursos e discursos, ou de sermões eloqüentes, mas sim pela ação dos seres humanos sobre o mundo". Supõe, assim, a conjunção entre teoria e prática, na qual ambas vão se constituindo, fazendose em um movimento permanente da prática à teoria e desta, a uma nova prática (GUTIÉRREZ, 1988).

Em "Pedagogia da Autonomia", Freire (1996) apresenta saberes necessários à prática educativa libertadora, evidenciando pontos determinantes, a saber: (1) Não há docência sem discência, de modo que o ato de ensinar exige alguns critérios, entre eles, rigorosidade metódica; pesquisa; respeito aos saberes dos educandos; criticidade; estética e ética; a corporeificação das palavras pelo exemplo; risco e aceitação do novo e rejeição a qualquer forma de discriminação; reflexão critica sobre a prática; reconhecimento e assunção da identidade cultural. (2) Ensinar não é transferir conhecimento, de modo que o ato de ensinar exige: consciência do inacabamento; reconhecimento do ser condicionado; respeito a autonomia do ser do educando; bom senso; humildade, tolerância e luta em defesa dos direitos dos educandos; apreensão da realidade; alegria e esperança; convicção de que a mudança é possível; curiosidade. (3) Ensinar é uma especificidade humana, de modo que o ato 
de ensinar exige: segurança, competência profissional e generosidade; comprometimento; compreender que a educação é uma forma de intervenção no mundo; liberdade e autoridade; tomada consciente de decisões; saber escutar.

A sinergia do pensamento Freireano abarca diferentes áreas do conhecimento e interfere na prática de diferentes profissões, reafirmando que o ato pedagógico é também um ato político, no qual é realçada a necessidade e o poder do coletivo, no intuito de construir o destino que se deseja para a sociedade como um todo.

\section{PRÁtICAS PARTICIPATIVAS NO DESIGN, PENSAMENTO FREIREANO E SUAS RELAÇÕES}

O pensamento Freireano e a filosofia do design participativo têm como pressupostos os processos de inclusão. Ao se analisar os pontos fortes de suas correntes de pensamento, definem-se relações convergentes e complementares, conforme Quadro 1, onde são apontados paralelamente os elementos comuns entre ambas as vertentes:

\begin{tabular}{|c|c|c|}
\hline & Design Participativo & Pedagogia Freireana \\
\hline & \multicolumn{2}{|c|}{ (a) Prática inclusiva } \\
\hline & \multicolumn{2}{|c|}{ (b) Prática problematizadora (desafiadora) } \\
\hline & \multicolumn{2}{|c|}{ (c) Prática dialógica } \\
\hline & \multicolumn{2}{|c|}{ (d) Prática reflexiva } \\
\hline & \multicolumn{2}{|c|}{ (e) Prática criativa } \\
\hline & \multicolumn{2}{|c|}{ (f) Prática investigativa } \\
\hline & \multicolumn{2}{|c|}{ (g) Prática da criticidade (Criticismo) } \\
\hline & \multicolumn{2}{|c|}{ (h) Prática da construção coletiva do saber } \\
\hline & \multicolumn{2}{|c|}{ (i) Prática da ação-reflexão } \\
\hline & \multicolumn{2}{|c|}{ (j) Prática da experimentação } \\
\hline & \multicolumn{2}{|c|}{ (k) Prática implementadora } \\
\hline & \multicolumn{2}{|c|}{ (I) Prática transformadora } \\
\hline & \multicolumn{2}{|c|}{ (m) Prática da aprendizagem } \\
\hline
\end{tabular}

Fonte: Elaborado pelos autores, com base na pesquisa realizada.

Todos esses pontos referem-se a uma filosofia de pensamentos e ações que dialogam entre si, onde uma depende da outra para existir, conforme explicitado na sequência através das letras correspondentes a cada um dos pontos de convergência do Quadro 1.

A prática da inclusão (a), tanto na educação libertadora quanto no design participativo, considera que as pessoas devem ter oportunidades iguais perante os fatos. Para Moraes e Santa Rosa (2012), a filosofia do design participativo se relaciona com o aspecto político e sociológico, onde as pessoas devem ter oportunidades de refletir (d) e, através do pensamento crítico (g) influenciar seu próprio território, criando (e) e implementando soluções (k). Além disso, para os autores, a atividade de design carrega consigo a responsabilidade de melhorar a qualidade de vida dos indivíduos impactados pelo sistema/ produto/ organização ou ambiente. Isso vai ao encontro do pensamento Freireano, que acredita na problematização (b) como mola propulsora para a transformação do ser humano e de suas relações com o mundo, 
exercendo sobre ele uma intersubjetivação das consciências (i) traduzida em açãoreflexão.

Para Freire, a prática problematizadora (b) carrega consigo uma situação desafiadora, na qual o ser humano se projeta como sujeito de busca, não mais como objeto. Ao se fazer sujeito, o ser humano efetiva uma ação transformadora (I) que resulta em protagonismo e não mais opressão, despertando sua conscientização social e política, tendo como resultado a consciência do seu pertencimento ao mundo e a criticidade sobre os fatos.

O pensamento Freireano defende que o sacrifício da reflexão humana resulta em ativismo, a partir da relação dialógica (c) entre os seres humanos:

\begin{abstract}
A existência, porque humana, não pode ser muda, silenciosa, nem tampouco pode nutrir-se de falsas palavras, mas de palavras verdadeiras, com que os homens transformam o mundo. Existir, humanamente, é pronunciar o mundo, é modificá-lo. (...) Não é no silencio que os homens se fazem, mas na palavra, no trabalho, na ação-reflexão (...) direito de todos os homens. Precisamente por isto, ninguém pode dizer a palavra verdadeira sozinho, ou dizê-la para os outros, num ato de prescrição, com o qual rouba a palavra dos demais (FREIRE, 1987, p.78).
\end{abstract}

Para Freire (1987) na prática dialógica (c) da ação, os sujeitos se encontram em colaboração para a transformação do mundo. $E$, também, nessa mesma condição, $O$ design participativo busca, com as pessoas, criar soluções para seus problemas. Assim, os sujeitos dialógicos se voltam sobre a realidade mediatizadora que, problematizada, os desafia, exercendo uma análise crítica sobre a realidade-problema. É a partir dessa relação que acontece a construção coletiva do saber (h).

Ao se analisar uma das diversas técnicas de inclusão de design participativo disponíveis, o Brainstorming ${ }^{1}$ - que, assim como as demais técnicas de inclusão, propõe o engajamento dos participantes por meio do diálogo, da troca de saberes, para que a prática criativa e reflexiva aconteça -, é possível perceber conexões com o pensamento Freireano a partir da definição das regras básicas do Brainstorming: 1. Concentrar-se no problema para gerar soluções: prática problematizadora (b), investigativa (f) e critica (g); 2 . Não julgar, pois não existem ideias ruins e todos têm o direito de se pronunciar: prática inclusiva (a); 3. Encorajar a participação do outro, pois qualquer tipo de ideia, mesmo que não pareça realista, pode inspirar outra pessoa a fazer uma nova proposta: prática inclusiva (a); 4. Saber ouvir, pois todas as ideias merecem ser ouvidas, do começo ao fim: prática dialógica (c); 5. Somar, construir a partir das ideias dos demais: prática da construção coletiva do saber (h).

Ao se considerar a prática do Design Thinking ${ }^{2}$, igualmente pautada no processo participativo, o pensamento presente na pedagogia Freireana pode ser percebido nas cinco fases distintas do seu processo metodológico (do Design Thinking), sendo a primeira a da DESCOBERTA, na qual, a partir da inclusão (a), os sujeitos da ação passam a dialogar (c) e entender o desafio por meio da investigação crítica (g). Nesta fase, a troca de saberes (h) constrói diferentes visões sobre um mesmo

\footnotetext{
${ }^{1}$ Método criativo para geração de ideias, a partir da definição de um problema. É realizado em grupo, composto por um facilitador e demais pessoas convidadas, que variam em níveis de expertise, a fim de fugir de uma visão tradicional sobre o problema.

${ }^{2}$ Processo de inovação centrada no ser humano que, entre outros aspectos, enfatiza a observação, a colaboração e o aprendizado acelerado.
} 
problema. Na segunda fase, a da INTERPRETAÇÃO, a ação dialógica (c) permite a conscientização social-política, constituindo um ponto de vista convergente e convincente, tornando os sujeitos ativos sobre o problema. Já na terceira fase, a da IDEAÇÃO, a ação-reflexão (i) coletiva, cria, por meio da prática criativa (e), soluções encorajadas de forma expansiva e sem amarras (ação libertadora), visando o bem comum; Na fase da EXPERIMENTAÇÃO, ao se implementar (k) a solução gerada para o problema, as ideias tornam-se tangíveis por meio da ação-reflexão (i). A aprendizagem (m) acontece a partir do momento que se compartilha o resultado com os demais sujeitos, presentes no contexto da problematização (b), uma vez que são expostas diferentes visões de mundo, sem julgamento, pois essas visões irão agregar valor à solução idealizada. Na quinta e última fase, EVOLUÇÃO, são desenvolvidos os conceitos da ideia no tempo, considerando e envolvendo a sociedade, observando como o contexto de uma experiência (j) afeta o mundo e cria aprendizados ( $\mathrm{m}$ ).

Na prática pedagógica, os espaços também são pensados de modo a promover uma melhor sinergia entre os sujeitos da ação. Do Instituto Paulo Freire, o pensador Cortella (1998), ao fazer analogia com uma cena teatral, propõe que o espaço onde a educação acontece deva ser um ambiente que requer atenção continua. Nesse espaço cênico, deve haver um ator principal que sabe interpretar e catalisar os sentidos e uma plateia disposta a viver voluntariamente emoções. Portanto, a distribuição do espaço é orientada para situar o indivíduo em um nível que possa ser percebido frente aos demais, permitindo-lhe, inclusive, liberdade de movimentação para uma melhor relação interpessoal. Nesse espaço, os sujeitos estão dispostos em formato de arena, tendo como ponto de referência a presença do ator. $\mathrm{O}$ autor destaca ainda que a construção do conhecimento pautada nessa premissa, entre outros componentes, conduz à elevação do caráter lúdico do processo, tendo como responsabilidade a promoção de uma partilha de conhecimentos agradável e justa. Assim, cada um dos envolvidos traz o que tem para trocar e não leva consigo nenhuma perda, pois todos se esforçam para que cada um fique com tudo.

$\mathrm{Na}$ relação do Design Thinking, especificamente com os espaços de aprendizagem, é possível perceber essa relação exposta por Cortella e, ao mesmo tempo, com o chamado círculo de cultura. Para Freire (2001), a prática do "círculo de cultura" faz com que os participantes da ação sintam-se verdadeiramente participando, enquanto sujeitos, de uma experiência real. Para o design esse viés é também preceito, ao se estabelecer uma experiência concreta onde a relação dialógica e lúdica flui de modo a permitir que as pessoas envolvidas sejam criativamente estimuladas, tanto no que diz respeito ao contato com uma disposição espacial diferenciada, quanto no estímulo a um método dinâmico que propõe a solução de desafios.

$\mathrm{Na}$ contemporaneidade dos fatos, o Jornal do Brasil (2014) observa que o Design Thinking tem contribuído com educadores na problemática de repensar as relações ensino-aprendizagem, de modo a criar meios para que educadores e educandos se sintam mais motivados nos processos de aprendizagem.

Tal proposta, ainda segundo o Jornal Brasil (2014), tem por caráter desenvolver a capacidade de cada aluno de pensar criticamente e inovar, para ter conscientemente condições de tornar o mundo um lugar melhor. O resultado é uma filosofia compartilhada de ensino e aprendizagem que permite discutir uma reforma nacional do sistema de ensino, na qual a base requer uma abordagem que deve ser construída 
coletivamente.

Para Moraes e Schmitz (2013) é o método pedagógico de Freire que sustenta a ação da prática participativa do design em seu processo educativo. Isso ocorre porque tem como pressuposto uma relação horizontal entre sujeitos que possuem coresponsabilidade no processo de aprendizagem e na busca por soluções, o que alude ao pensamento de Freire, quando afirma:

\begin{abstract}
Não devo julgar-me como profissional "habitante" de um mundo estranho; mundo de técnicos e especialistas salvadores dos demais, donos da verdade, proprietários do saber, que devem ser doados aos "ignorantes e incapazes". Habitantes de um gueto, de onde saio messianicamente para salvar os "perdidos", que estão fora. Se procedo assim, não me comprometo verdadeiramente como profissional nem como homem. Simplesmente me alieno (FREIRE, 2011 apud MORAES e SCHMITZ, 2013).
\end{abstract}

Há, portanto, um compromisso que tangencia as ações participativas, tanto do profissional do design quanto do educador. Ao refletir sobre a essência do design e sua intencionalidade, fica perceptível seu compromisso e contribuição social, sendo ciência capaz de propor novas soluções frente a problemas diversos. E, na relação com seu campo de atuação social, o designer torna-se sujeito responsável pela interlocução de projetos, guiando uma aprendizagem significativa, que possibilite às pessoas o reconhecimento e utilização adequada de recursos com vistas à mudança social. Essa também pode ser a grande meta da educação, sendo uma resposta à problematização mundial, no que diz respeito, entre outros aspectos, à desigualdade social.

\title{
6 CONSIDERAÇÕES FINAIS
}

Esse estudo preliminar resulta em reflexões pertinentes à prática educativa tanto no que se refere ao design participativo quanto à pedagogia Freireana - e requer maiores aprofundamentos nas demais metodologias de design, onde se percebe sinergia. As contribuições de Paulo Freire podem ser ainda melhor explicitadas, considerando, inclusive, outros educadores que mantêm seus pressupostos.

Paulo Freire pode ser estudado no âmbito do design para além das metodologias sistematizadas, fazendo-se presente também nas salas de aula dos cursos de design, onde a prática da educação libertadora deve acontecer, bem como nos escritórios de design e em outras culturas organizacionais, nas comunidades onde o design social atua, promovendo inclusão e melhoria da qualidade de vida. É possível, portanto, considerar que há preocupação com um sistema flexível, alimentado constantemente pela imaginação, pela criatividade e pelo compromisso dos participantes em promover formação da consciência humana, para melhor operar a mudança social, tão necessária ao mundo real e complexo em que se vivemos.

E, como acredita Paulo Freire, a educação é um projeto social para a libertação, tendo, em seu propósito, o diálogo crítico e a comunhão permanente, com vistas à superação das desigualdades e ênfase no caráter participativo em todos os âmbitos da vida humana.

Por fim, cabe reforçar a importância das relações entre as práticas participativas no design e os princípios pedagógicos Freireanos, cujas aproximações preliminares puderam ser abordadas no presente artigo. Considerando que ambos 
possuem um viés pedagógico capaz de propor reflexões com vistas à superação dos desafios sociais contemporâneos, é imprescindível que os profissionais nelas atuantes lancem mão dos conhecimentos convergentes e complementares aqui abordados para, juntos, proporem soluções plausíveis no que diz respeito às relações de ensinoaprendizagem, interagindo e dialogando, na condução de metodologias criativas e inovadoras voltadas às práticas participativo-pedagógicas.

\section{REFERÊNCIAS}

AMSTEL, Frederick M.C. Van. Das interfaces às interações: design participativo do portal broffice.org. Dissertação de Mestrado. Universidade Tecnológica Federal do Paraná - UTPR, 2008.

BENAVIDES-PUERTO, Henry. Tecnologias Sociais e Design Participativo. Cadernos de trabalho. INCUBA - Universidade do Estado da Bahia - UNEB, 1999.

CORTELLA, Mário Sergio. A escola e o conhecimento: fundamentos epistemológicos e políticos. São Paulo: Cortez Editora, 1998.

FIORI, Ernani Maria. Prefácio: Pedagogia do oprimido. 17ạ ed. Rio de Janeiro, Paz e Terra, 1987.

FREIRE, Paulo. Pedagogia do oprimido. 17a ed. Rio de Janeiro, Paz e Terra, 1987.

Educação e Mudança. 28aㅡ. ed. Rio de Janeiro: Paz e Terra, 1979.

Pedagogia da autonomia: saberes necessários à prática educativa. Rio de

Janeiro: Paz e Terra, 1996.

A importância do ato de ler em três artigos que se completam. $42^{a}$ ed. São

Paulo, Cortez, 2001.

GADOTTI, Moacir. Prefácio: Educação e Mudança. Rio de Janeiro: Paz e Terra, 1979.

GUTIÉRREZ, Francisco. Educação como práxis política. Tradução de Antônio Negrinho. São Paulo: Summus, 1988.

JORNAL DO BRASIL. Design Thinking chega às salas de aula. Disponível na internet por: www.jb.com.br/ciencia-e-tecnologia/noticias/2014/01/22/design-thinking-chega-assalas-de-aula/. Acesso em: 27/01/14.

MORAES, Ana Maria; SANTA ROSA, José Guilherme. Design Participativo, técnicas para inclusão de usuários no processo de ergodesign de interfaces. Rio de Janeiro: Rio Books, 2012.

MORAES, Flávia; SCHMITZ, Mariana de Oliveira. Ferramentas metodológicas aplicáveis em projetos de design em cooperação com grupos produtivos: um levantamento preliminar. Universidade do Estado de Minas Gerais - UEMG. Escola de Design - ED. Belo Horizonte, 2013.

NASCIMENTO, Alex Sandro Alves do. As relações de poder na escola: o canto da contestação na música Another brick in the Wall, de Pink Floyd. Anais do IV Colóquio Internacional Cidadania Cultural: diálogos de gerações, 2009.

SILVA, Nivaldo Aureo Nascimento da. Abordagens Participativas para o Design: Metodologias e plataformas sociotécnicas como suporte ao design interdisciplinar e aberto a participação. Dissertação (mestrado). Pontifícia Universidade Católica de São Paulo - PUC-SP, 2012. 